Pediat. Res. 6: 664-674 (1972)

Growth and development growth retardation

hypopituitarism

human growth hormone

thyroid hormone

\title{
Acute and Long-Term Responsiveness to Growth Hormone in Children with Short Stature
}

\author{
Jerome A. Grunt ${ }^{[38]}$ and Alfonso R. Enriguez \\ Department of Pediatrics, Yale University School of Medicine, and the Yale New Haven Hospital, New Haven, Connecticut, USA
}

\section{Extract}

Acute and long-term responsiveness to human growth hormone ( $\mathrm{HGH}$ ) has been studied in 25 short children. Five had hypopituitarism; 10 had no demonstrable endocrinopathy; 4 were above the 97th percentile for weight but below the 3rd percentile for height; and 6 were small-for-date. When treated with thyroid hormone as well as $\mathrm{HGH}, 4$ of the 5 hypopituitary patients grew significantly. However, 7 of the nonhypopituitary patients with normal or high levels of endogenous $\mathrm{HGH}(35 \%)$ also grew with $\mathrm{HGH}$ treatment. Prior to $\mathrm{HGH}$ treatment, this group grew at an average rate of $3.4 \mathrm{~cm} / \mathrm{yr}$; with $\mathrm{HGH}$, this rate increased to $8.8 \mathrm{~cm} / \mathrm{yr}$. Acute responses to HGH did not correlate well with long-term response. Reassessment of the criteria used to select patients for treatment is discussed.

\section{Speculation}

A significant number of dwarfed children with normal levels of HGH may grow when they are treated with growth hormone. Neither endogenous HGH levels nor acute responses to $\mathrm{HGH}$ found in these studies correlated well with the subsequent $\mathrm{HGH}$-altered growth rate. Since predictions of which dwarfed child with decreased growth rate will grow when treated with $\mathrm{HGH}$ are poor, there is little justification for restricting such therapy to the hypopituitary patient. Although less restricted use of HGH is suggested, caution must be employed, since such therapy may be associated with development of $\mathrm{HGH}$ antibodies and subsequent diminution of growth.

\section{Introduction}

Although there are many studies of acute and longterm effects of HGH in short children, only a few investigators have attempted to relate acute responses to the HGH-altered growth rate [5, 11, 15-17, 21, 29]. Despite the likelihood that synthetic growth hormone will be available in the future, HGH is still in short supply. If acute responsiveness to the hormone could be used as a criterion to determine which short patients will grow with this therapy, available HGH could be used more effectively. In addition, even if an adequate supply of growth hormone were to become available soon, it would be in the patients' best interest to treat only those short individuals who would respond with an increased rate of growth. This investigation has attempted to correlate acute responses to HGH with altered rates of growth following long-term HGH treatment in 4 different types of dwarfed children.

\section{Patients}

Studies were carried out on 25 children whose heights were below the third percentile. Physical findings and 
Responsiveness to growth hormone

Table I. Physical characteristics of patients with short stature

\begin{tabular}{|c|c|c|c|c|c|c|c|c|c|}
\hline Patient & Sex & $\begin{array}{c}\text { Age, }, \\
\text { yr-mo }\end{array}$ & Height, cm & $\begin{array}{c}\text { Ht. age, } \\
\text { yr-mo }\end{array}$ & $\mathrm{SD}$ & Weight, kg & $\begin{array}{l}\text { \% of ideal } \\
\text { wt for ht }\end{array}$ & $\begin{array}{c}\text { Bone age, } \\
\text { yr-mo }\end{array}$ & $\begin{array}{c}\text { Sexual } \\
\text { development }\end{array}$ \\
\hline \multicolumn{10}{|c|}{ Hypopituitarism } \\
\hline$B W$ & $M$ & $11-2$ & 122.5 & $7-0$ & -4 & 31.5 & 132 & $8-0$ & 1 \\
\hline$W M$ & $M$ & $16-7$ & 135.3 & $9-2$ & -5 & 33.8 & 114 & $12-0$ & 1 \\
\hline$R G$ & M & $14-2$ & 131.5 & $8-3$ & -5 & 37.4 & 136 & $10-0$ & 1 \\
\hline$B S$ & $F$ & $13-1$ & 125.2 & $7-8$ & -5 & 33.1 & 135 & $5-3$ & 1 \\
\hline$S P$ & $\hat{M}$ & $13-1$ & 144.0 & $11-0$ & -2 & 62.2 & 178 & $10-0$ & 1 \\
\hline Mean & & $13-7$ & 131.7 & $8-7$ & & 39.6 & 139.3 & $9-2$ & \\
\hline$\pm \operatorname{SEM}$ & & $\pm 0-7$ & \pm 3.4 & \pm 0.7 & & \pm 5.1 & \pm 9.4 & \pm 1.1 & \\
\hline \multicolumn{10}{|c|}{ Idiopathic short stature } \\
\hline$W F$ & $\mathrm{M}$ & $11-6$ & 127.0 & $7-10$ & -3 & 23.0 & 91 & $8-0$ & I \\
\hline$T W$ & $\mathrm{M}$ & $10-0$ & 126.0 & $7-9$ & -2 & 22.8 & 90 & $8-6$ & 1 \\
\hline$N M$ & $\mathrm{~F}$ & $10-8$ & 113.5 & $5-5$ & -6 & 19.9 & 100 & $6-10$ & 1 \\
\hline$N P$ & $M$ & $10-5$ & 113.0 & $5-6$ & -5 & 19.8 & 95 & $6-6$ & 1 \\
\hline$J B$ & $M$ & $13-0$ & 125.3 & $8-0$ & -5 & 23.3 & 94 & $9-0$ & 1 \\
\hline$C R$ & $\mathrm{~F}$ & $5-9$ & 98.0 & $3-3$ & -4 & 14.2 & 93 & $2-0$ & $\hat{l}$ \\
\hline TO & $\mathrm{M}$ & $8-7$ & 95.2 & $2-10$ & -7 & 12.8 & 88 & $3-0$ & i \\
\hline$M D$ & $M$ & $9-2$ & 117.0 & $6-3$ & -3 & 21.9 & 101 & $7-9$ & $\hat{1}$ \\
\hline$T S$ & $\mathrm{M}$ & $12-0$ & 125.3 & $7-9$ & -4 & 23.9 & 97 & $8-0$ & 1 \\
\hline$E S$ & $\mathrm{~F}$ & $7-1$ & 108.0 & $4-7$ & -2 & 17.6 & 98 & $3-10$ & 1 \\
\hline Mean & & $9-10$ & 114.8 & $6-11$ & & 19.9 & 94.7 & $6-5$ & \\
\hline$\pm \mathrm{SEM}$ & & $\pm 0-8$ & \pm 3.5 & $\pm 0-7$ & & \pm 1.2 & \pm 1.3 & $\pm 0-9$ & \\
\hline \multicolumn{10}{|c|}{ Short obese } \\
\hline$N R$ & $\mathrm{M}$ & $16-2$ & 150.5 & $12-5$ & -2 & 70.5 & 174 & $14-0$ & 2 \\
\hline$T P$ & $\mathbf{M}$ & $7-8$ & 111.0 & $5-4$ & -3 & 39.3 & 207 & $5-0$ & 1 \\
\hline$J S$ & $\mathrm{M}$ & $14-8$ & 142.5 & $10-10$ & -3 & 68.1 & 200 & $12-6$ & 2 \\
\hline$J R$ & $\mathrm{~F}$ & $4-0$ & 95.0 & $2-11$ & -2 & 22.4 & 158 & $3-3$ & 1 \\
\hline Mean & & $10-7$ & 124.8 & $8-0$ & & 50.1 & 184.8 & $8-8$ & \\
\hline$\pm \mathrm{sEM}$ & & $\pm 2-6$ & \pm 11.3 & $2-0$ & & \pm 10.1 & \pm 9.9 & $\pm 2-4$ & \\
\hline \multicolumn{10}{|c|}{ Small-for-date } \\
\hline$L P$ & $\mathrm{~F}$ & $6-6$ & 90.0 & $2-5$ & -6 & 11.2 & 86 & $3-0$ & 1 \\
\hline$R P$ & $M$ & $7-9$ & 94.0 & $2-9$ & -7 & 13.2 & 94 & $5-0$ & 1 \\
\hline$R N$ & $\mathrm{~F}$ & $8-5$ & 104.0 & $4-0$ & -4 & 14.9 & 89 & $7-10$ & 1 \\
\hline$J C$ & $\mathrm{M}$ & $7-2$ & 111.5 & $5-2$ & -3 & 18.0 & 95 & $5-0$ & I \\
\hline$E R$ & $M$ & $8-7$ & 111.7 & $6-3$ & -4 & 24.5 & 129 & $9-0$ & 1 \\
\hline$P S$ & $\mathrm{M}$ & $6-5$ & 102.0 & $3-10$ & -4 & 14.2 & 87 & $5-9$ & 1 \\
\hline Mean & & $7-6$ & 102.2 & $4-8$ & & 16.0 & 96.7 & $5-11$ & \\
\hline$\pm \mathrm{SEM}$ & & $\pm 0-4$ & \pm 3.3 & $\pm 0-7$ & & \pm 1.8 & \pm 6.1 & $\pm 0-10$ & \\
\hline
\end{tabular}

${ }^{1}$ When human grow th hormone therapy was begun.

${ }^{2}$ According to Tanner [24].

endocrine evaluations are presented in Tables $I$ and II. Patients were classified in 4 groups on the basis of history, physical findings, and endocrine evaluation.

Five patients had hypopituitarism of unknown cause. The mean chronological age for this group was $137 / 12$ yr; mean height age, $87 / 12 \mathrm{yr}$; and mean bone age, $92 / 12$ yr. All were overweight for height. Skull films were normal. None received other hormonal therapy during this study. Their rates of growth prior to HGH treatment ranged from 3.5 to $5.7 \mathrm{~cm} / \mathrm{yr}$ (Table III). None had a maximal HGH level in excess of 5 $\mathrm{ng} / \mathrm{ml}$ after exercise, insulin, and arginine. The PBI was low in one and normal in four but 24-hr RAI uptake was $13 \%$ or less in all five. The four patients given thyroid-stimulating hormone (TSH) responded with an increase in 24-hr RAI uptake. Adrenal responses to ACTH were normal as were responses to metyrapone in four of these patients. All five were sexually immature with normal gonadotropins for their stage of development.

Ten individuals had idiopathic short stature. Their mean chronological age was $910 / 12 \mathrm{yr}$; mean height 
Table II. Endocrine evaluation of patients with short stature ${ }^{1}$

\begin{tabular}{|c|c|c|c|c|c|c|c|c|c|}
\hline \multirow{3}{*}{ Patient } & \multirow{3}{*}{$\begin{array}{l}\mathrm{HGH} \text { peak, } \\
\mathrm{ng} / \mathrm{ml}\end{array}$} & \multicolumn{2}{|c|}{$17-\mathrm{OH}, \mathrm{mg} / 24 \mathrm{hr}$} & \multicolumn{2}{|c|}{ Comp. S, mg/24 hr } & \multirow{3}{*}{$\begin{array}{c}\text { PBI } \\
\mu \mathrm{g} / 100 \mathrm{ml}\end{array}$} & \multicolumn{2}{|c|}{ 24-hr RAI, \% uptake } & \multirow{3}{*}{$\begin{array}{c}\text { Urinary } \\
\text { gonadotropin, } \\
\text { milliunits }\end{array}$} \\
\hline & & Pre & Post & Pre & Post & & Pre & Post & \\
\hline & & \multicolumn{2}{|c|}{$\mathrm{ACTH}$} & \multicolumn{2}{|c|}{ Metyrapone } & & \multicolumn{2}{|c|}{ TSH } & \\
\hline \multicolumn{10}{|c|}{ Hypopituitarism } \\
\hline$B W$ & 3.7 & 3.1 & 16.0 & $<0.1$ & 8.1 & 5.4 & 9 & - & - \\
\hline$W M$ & 5.0 & 0.6 & 16.0 & - & 一 & 4.0 & 13 & 19 & $<6.5$ \\
\hline$R G$ & 1.0 & 6.7 & 16.0 & $<0.1$ & 8.4 & 4.2 & 11 & 28 & - \\
\hline$B S$ & 1.3 & 1.4 & 14.0 & $<0.1$ & 4.6 & 2.4 & 9 & 22 & 6.5 \\
\hline$S P$ & 0.5 & 4.0 & 20.0 & 0.1 & 0.4 & 4.6 & 8 & 29 & $<6.5$ \\
\hline \multicolumn{10}{|c|}{ Idiopathic short stature } \\
\hline$W F$ & 20.0 & 7.4 & 19.0 & $<0.1$ & 5.6 & 6.2 & 20 & - & $<6.5$ \\
\hline$T W$ & 10.0 & 2.8 & 12.0 & $<0.1$ & 4.4 & 6.1 & 17 & - & $<6.5$ \\
\hline$N M$ & 96.0 & 3.2 & 11.8 & 3.8 & 34.0 & 6.4 & 22 & - & $<6.5$ \\
\hline$N P$ & 10.0 & 2.2 & 9.7 & 0.4 & 8.0 & 6.0 & 15 & - & $<6.5$ \\
\hline$J B$ & 7.0 & 3.4 & 18.0 & 0.3 & 27.0 & 6.2 & 21 & - & $<6.5$ \\
\hline$C R$ & 10.0 & 1.5 & 14.0 & 一 & - & 8.0 & 30 & - & - \\
\hline$T O$ & 8.4 & 2.6 & 11.0 & $<0.1$ & 9.8 & 3 & 24 & - & $<6.5$ \\
\hline$M D$ & 10.4 & 1.2 & 6.2 & $<0.1$ & 7.9 & 6.9 & 16 & 46 & 13 \\
\hline$T S$ & 21.4 & 2.5 & 6.9 & $<0.1$ & 6.5 & 6.5 & 16 & 26 & 一 \\
\hline$E S$ & 8.0 & 4.9 & 13.0 & $<0.1$ & 3.9 & 7.5 & 24 & - & - \\
\hline \multicolumn{10}{|c|}{ Short obese } \\
\hline$N R$ & 10.5 & 3.9 & 9.9 & $<0.1$ & 11.0 & 5.2 & 14 & 38 & - \\
\hline$T P$ & 1.2 & 2.5 & 9.2 & - & - & 6.2 & 10 & - & - \\
\hline$J S$ & 2.2 & 5.9 & 29.0 & $<0.1$ & 15.0 & 6.3 & 14 & 37 & - \\
\hline$J R$ & 3.0 & 3.0 & 7.0 & - & - & 11.2 & 19 & - & - \\
\hline \multicolumn{10}{|c|}{ Small-for-date } \\
\hline$L P$ & 29.0 & 0.8 & 3.7 & $<0.1$ & 1.9 & 9.0 & 11 & 25 & $<6.5$ \\
\hline$R P$ & 6.9 & 1.1 & 7.9 & $<0.1$ & 1.8 & 7.4 & 11 & 21 & $<6.5$ \\
\hline$R N$ & 49.0 & 1.7 & 12.0 & $<0.1$ & 0.7 & 6.5 & 15 & 22 & 6.5 \\
\hline$J C$ & 50.0 & 1.1 & 3.7 & $<0.1$ & 5.7 & 6.7 & 22 & - & 6.5 \\
\hline$E R$ & 65.0 & 4.7 & 12.0 & 0.4 & 11.0 & 6.5 & 9 & 17 & 13 \\
\hline$P S$ & 56.0 & 0.9 & 4.5 & $<0.1$ & $<0.1$ & 7.5 & 18 & - & 13 \\
\hline
\end{tabular}

${ }^{1} \mathrm{HGH}$ : human growth hormone, 17-OH: 17-hydroxycorticosteroids, TSH: thyroid-stimulating hormone.

${ }^{2}$ Following exercise, and administration of insulin and arginine.

${ }^{3}$ Contaminated.

age, $611 / 12 \mathrm{yr}$; and mean bone age, $65 / 12 \mathrm{yr}$. All had average weight for height. Their annual pretreatment growth rates ranged from 1.3 to $6.8 \mathrm{~cm}$. Endocrine evaluation in this group was normal. None had a peak HGH level less than $7.0 \mathrm{ng} / \mathrm{ml}$ and the three patients with growth rates of less than $4 \mathrm{~cm} / \mathrm{yr}$ had peak $\mathrm{HGH}$ levels between 10 and $21 \mathrm{ng} / \mathrm{ml}$. PBI values were all normal and 24-hr RAI uptakes were all $15 \%$ or above. Adrenal function and urinary gonadotropins were normal.

Four patients were both short and grossly obese. All were more than 2 so below the mean for height and $158-207 \%$ of ideal weight for height. Their mean chronological age was $107 / 12 \mathrm{yr}$; mean height age, 8 $0 / 12 \mathrm{yr}$; and mean bone age, $88 / 12$ yr. Their pre- treatment rates of growth ranged from 2.3 to $3.8 \mathrm{~cm} /$ yr. Peak HGH levels were $3.0 \mathrm{ng} / \mathrm{ml}$ or less in three of the four patients. Three of the four had a 24-hr RAI uptake of $14 \%$ or less in spite of normal or elevated levels of PBI. In the two patients tested, the RAI increased after they were treated with TSH. Adrenal function was normal. Two of the four showed early sexual development.

Six patients were in the small-for-date group. All of these patients were born at term but had birth weights of $2 \mathrm{~kg}$ or less. Their mean chronological age was 7 $6 / 12 \mathrm{yr}$; mean height age, $48 / 12 \mathrm{yr}$; and mean bone age, $511 / 12$ yr. With one exception $(E R)$ their weights were essentially normal for their heights. Growth rates prior to HGH treatment in this group ranged from 1.6 
to $5.3 \mathrm{~cm} / \mathrm{yr}$. Their peak $\mathrm{HGH}$ levels ranged from 6.9 to $65.0 \mathrm{ng} / \mathrm{ml}$ (average, $42.7 \mathrm{ng} / \mathrm{ml}$ ). Endocrine studies gave mixed results. Although all six patients had normal PBI levels, three ( $L P, R P$ and $E R$ ) had 24-hr RAI uptakes below $15 \%$; the 24 -hr urinary 17 -hydroxycorticosteroid levels were $1.7 \mathrm{mg}$ or less in five of the six, and three $(L P, J C$, and $P S)$ responded poorly to ACTH; one patient $(P S)$ responded poorly to metyrapone; four had elevated urinary gonadotropins without evidence of advanced sexual development.

\section{Methods}

Bone age was obtained using the Atlas of Greulich and Pyle [10]. The patients were measured every three months starting at least one year prior to $\mathrm{HGH}$ administration and continuing throughout the study.

Height was expressed as height age and standard deviation (SD) from the mean value for age with respect to the standards of Bayer and Bayley [1].

Throughout the study, only Wilhelmi growth hormone was used. Treatment consisted of intramuscular injections of $2 \mathrm{IU} \mathrm{HGH}$ every other day. None of the patients experienced any abnormal responses which could be related to the hormone therapy.

All tests for evaluating $\mathrm{HGH}$ levels were carried out after a 12-hr overnight fast. Patients were kept in bed and given only water to drink during the test.

\section{Evaluation of Maximal HGH Levels}

Insulin Tolerance Test. Insulin was administered intravenously $(0.1 \mathrm{U} / \mathrm{kg})$ and blood samples were obtained $0,15,30,45,60,90$ and 120 min thereafter. Only those tests were utilized in which there was at least a $50 \%$ fall in blood sugar level.

Glucagon Tolerance Test. This test was carried out at completion of the insulin tolerance test using an intravenous injection of glucagon $(0.03 \mathrm{mg} / \mathrm{kg})$. Blood samples were obtained $15,30,45$ and $60 \mathrm{~min}$ thereafter.

Arginine Tolerance Test. This test utilized a $30-\mathrm{min}$ infusion of 1-arginine monohydrochloride [30]. The test dose was $5 \mathrm{~g}$ for patients aged $10 \mathrm{yr}$ or less and 10 $\mathrm{g}$ for patients older than $10 \mathrm{yr}$. Blood samples were obtained at $0,30,60,90$ and $120 \mathrm{~min}$.

Exercise. Patients ran over a fixed course for $15 \mathrm{~min}$. Blood specimens were obtained at beginning and end of the test.

\section{Evaluation of Acute Responses to HGH}

Nitrogen Balance. Nitrogen balance was determined for 6 days prior to start of HGH treatment and for 6 days during the daily injection of one IU HGH. Diets duplicated the patient's normal intake. Urine, stool, rejected food, and duplicate diets were analyzed.

Tolerance Tests. Both insulin and glucagon tolerance tests were performed on two occasions: prior to use of $\mathrm{HGH}$; and 4-10 days later, $4 \mathrm{hr}$ after the patients received 2 IU HGH intramuscularly.

\section{Laboratory Procedures}

HGH was measured using the double antibody radioimmunoassay method of Boden and Soeldner [2]. ${ }^{125} \mathrm{I}-\mathrm{HGH}$ [31], guinea pig antiserum to $\mathrm{HGH}$ [32], and rabbit antiserum to guinea pig gamma globulin [32] were obtained commercially. Free fatty acids (FFA) were determined by the method of Dole [6], blood sugar (BS) by a glucose oxidase method [28], and total nitrogen by Kjeldahl digestion [3] and direct Nesslerization [9]. Adrenal function was evaluated by measuring 24-hr urinary 17-hydroxycorticosteroids [22] before and during intravenous administration of 40 units ACTH over an 8-hr period, and by measuring 24-hr urinary Compound $S$ levels [19] before and after oral administration of $100 \mathrm{mg}$ metyrapone per kilogram body weight in 6 divided doses every $4 \mathrm{hr}$. This is a modification of the protocol suggested by Richmond et al. [19]. Urinary gonadotropins were evaluated using the method of Klinefelter et al. [13].

\section{Data Presentation}

In order to assess acute responses to $\mathrm{HGH}$, nitrogen balance study and insulin and glucagon tolerance tests which were made prior to HGH treatment were compared with tests conducted when patients were under the influence of HGH.

BS and FFA levels obtained during insulin tolerance tests and the BS level after glucagon administration were first calculated on the basis of percentage change from fasting levels. The percentage of the control value was then plotted and the areas described were determined by planimeter [33]. Areas described prior to the use of HGH were compared with those obtained after a single injection of 2 IU HGH.

The differences in nitrogen balance with and without HGH and the HGH-altered responses to insulin and glucagon were then compared with the long-term response to HGH (growth) using the rank correlation method of statistical analysis [7]. Individual acute responses as well as the peak HGH level for each patient are related graphically to the differences in growth rate subsequent to HGH therapy in Figures 1-5. 
Table III. Acute and long-term responses to human growth hormone (HGH) in patients with short stature

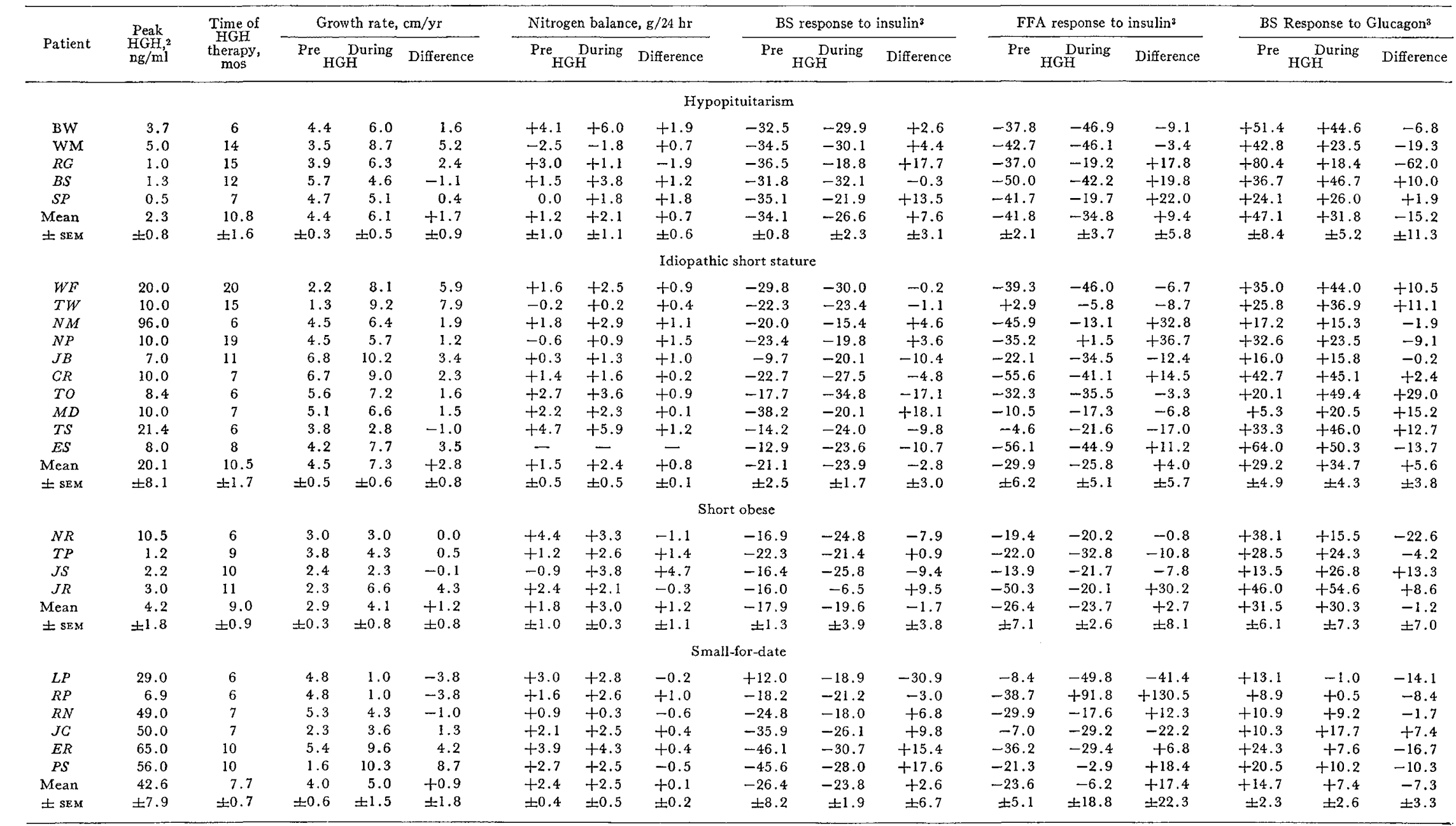

$1 \mathrm{BS}$ : blood sugar, FFA: free fatty acids.

2 Following exercise and administration of insulin and arginine.

3 Surface area under the curve, in $\mathrm{cm}^{2}$. 


\section{Results}

\section{HGH Levels}

The maximum $\mathrm{HGH}$ response following exercise, insulin and arginine in each patient is noted in Table III.

None of the hypopituitary patients had peak HGH levels which exceeded $5.0 \mathrm{ng} / \mathrm{ml}$. The maximum $\mathrm{HGH}$ response following insulin and arginine in 16 normal boys and girls ( 5 to 16 years old) in our laboratory is $18.1 \pm 2.2 \mathrm{ng} / \mathrm{ml}$ (mean $\pm \mathrm{sEM}$ ).

None of the patients with idiopathic short stature had a maximum $\mathrm{HGH}$ response of less than $7.0 \mathrm{ng} / \mathrm{ml}$.

With the exception of one patient $(N R)$, none of the short obese patients had peak HGH levels which exceeded $3.0 \mathrm{ng} / \mathrm{ml}$.

The maximum $\mathrm{HGH}$ responses in the small-for-date patients were among the highest of all patients in this study. Only one out of the six patients in this group (RP) had a peak HGH level below $29.0 \mathrm{ng} / \mathrm{ml}$.

\section{Growth Response to HGH (Table III and Figure 1)}

When treated only with growth hormone, one of five hypopituitary patients responded with a significantly increased rate of growth. However, when replacement doses of thyroid hormone were administered in addition to $\mathrm{HGH}$, three of these patients $(R G, B S$, and $S P$ ) increased their growth rates significantly $(8.6,9.7$, and $10.3 \mathrm{~cm} /$ yr respectively). One patient $(B W)$ continued to respond poorly despite the administration of thyroid hormone and testosterone in addition to HGH.

In the idiopathic short stature group four of $10 \mathrm{pa}-$ tients responded to long-term HGH treatment with an increase in growth rate by at least $3.4 \mathrm{~cm} / \mathrm{yr}$.

Only one of the four short obese patients responded to long-term HGH treatment with a significantly increased rate of growth ( $J R$ increased her growth rate by $4.3 \mathrm{~cm} / \mathrm{yr}$ ). None of the other patients in this group increased growth rate by as much as $1.0 \mathrm{~cm} / \mathrm{yr}$.

Two of the six small-for-date patients increased their growth rates by more than $4.0 \mathrm{~cm} / \mathrm{yr}$ while being treated with HGH. None of the others in this group did so. Three of these patients ( $L P, R P$, and $R N)$ actually grew at decreased rates while they were on therapy.

\section{Acute Responses to $\mathrm{HGH}$}

Data on the acute responses to HGH are presented in Table III and in Figures 2-5.

There was increased retention of nitrogen following HGH treatment (Fig. 2) in four of five hypopituitary patients, in all nine of the idiopathic short children who were studied in this manner (no nitrogen balance study was made for $E S$ ), in two of four short obese patients, and in three of six patients who were smallfor-date.

Four of the five hypopituitary patients responded

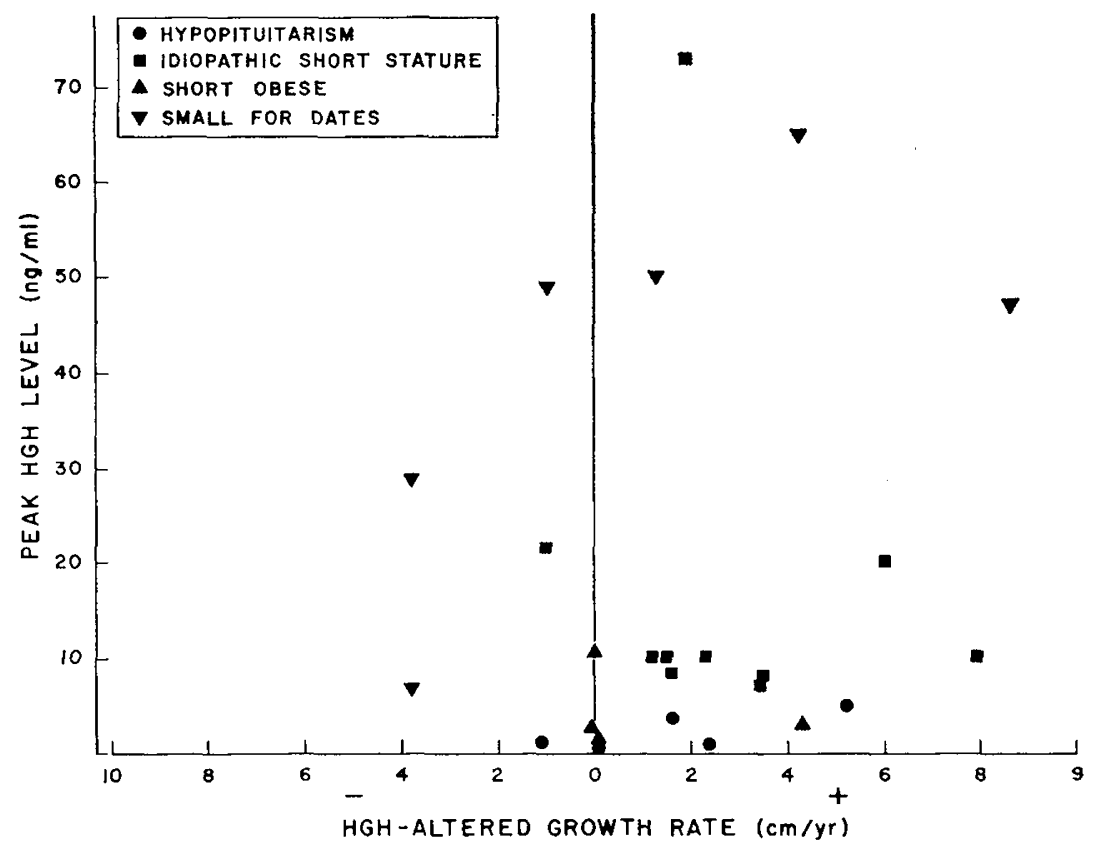

Fig. 1. Comparison of $\mathrm{HGH}$-altered growth rate and peak $\mathrm{HGH}$ levels. $H G H$; human growth hormone. 
acutely to HGH by decreasing the fall in the BS following insulin stimulation (Fig. 3). This type of response was present in only three of ten patients with idiopathic short stature, in two of four short obese patients, and in four of six patients who were smallfor-date.

When HGH was administered acutely, there was less of an insulin-induced drop in FFA levels (Fig. 4) in

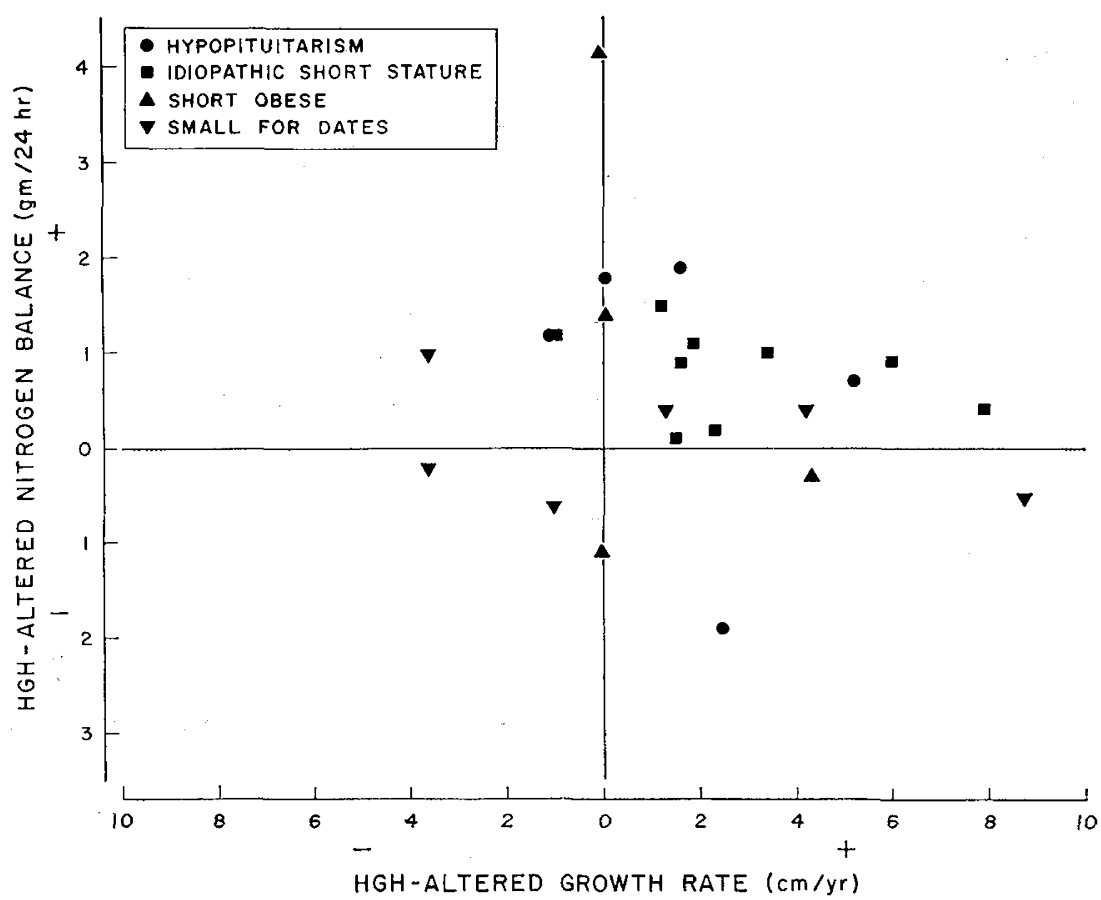

Fig. 2. Comparison of $\mathrm{HGH}$-altered growth rate and $\mathrm{HGH}$-altered nitrogen balance. $H G H$ : human growth hormone.

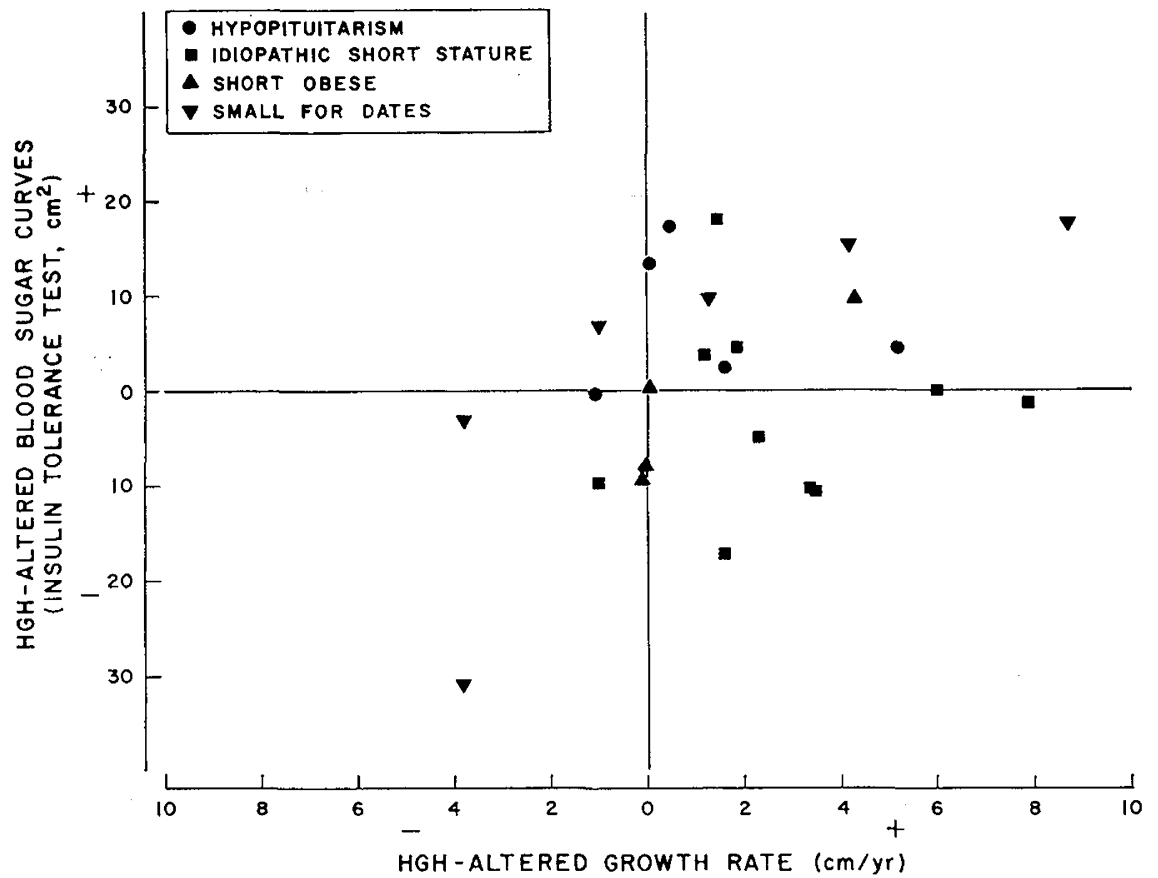

Fig. 3. Comparison of HGH-altered growth rate and acute HGH-altered blood sugar following insulin stimulation. HGH: human growth hormone. 
three of five hypopituitary patients, in four of ten patients with idiopathic short stature, in one of four short obese patients, and in four of six small-for-date patients.
The HGH-altered BS changes following glucagon stimulation (Fig. 5) revealed positive acute responses to $\mathrm{HGH}$ (an increase in BS concentration following glucagon administration): in two of five hypopituitary

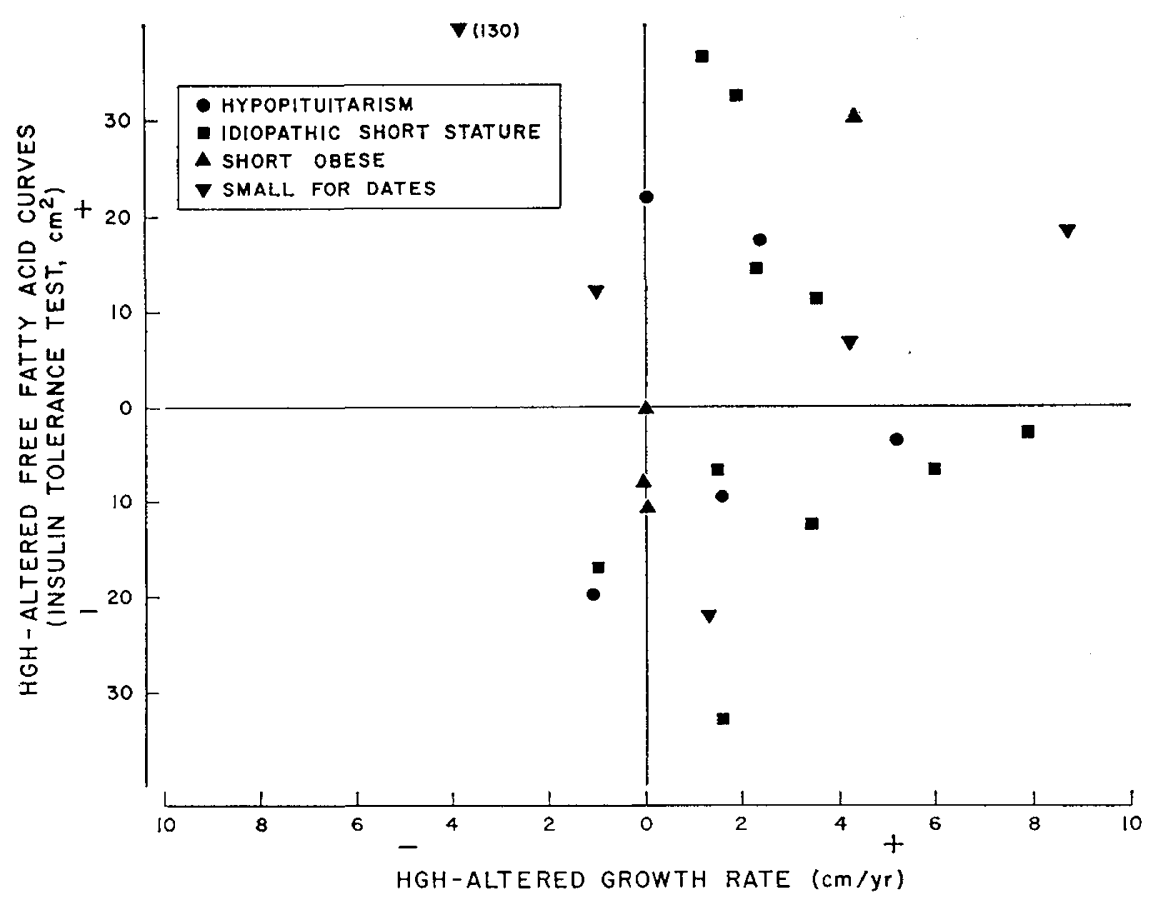

Fig. 4. Comparison of $\mathrm{HGH}$-altered growth rate and acute $\mathrm{HGH}$-altered free fatty acids following insulin stimulation. HGH: human growth hormone.

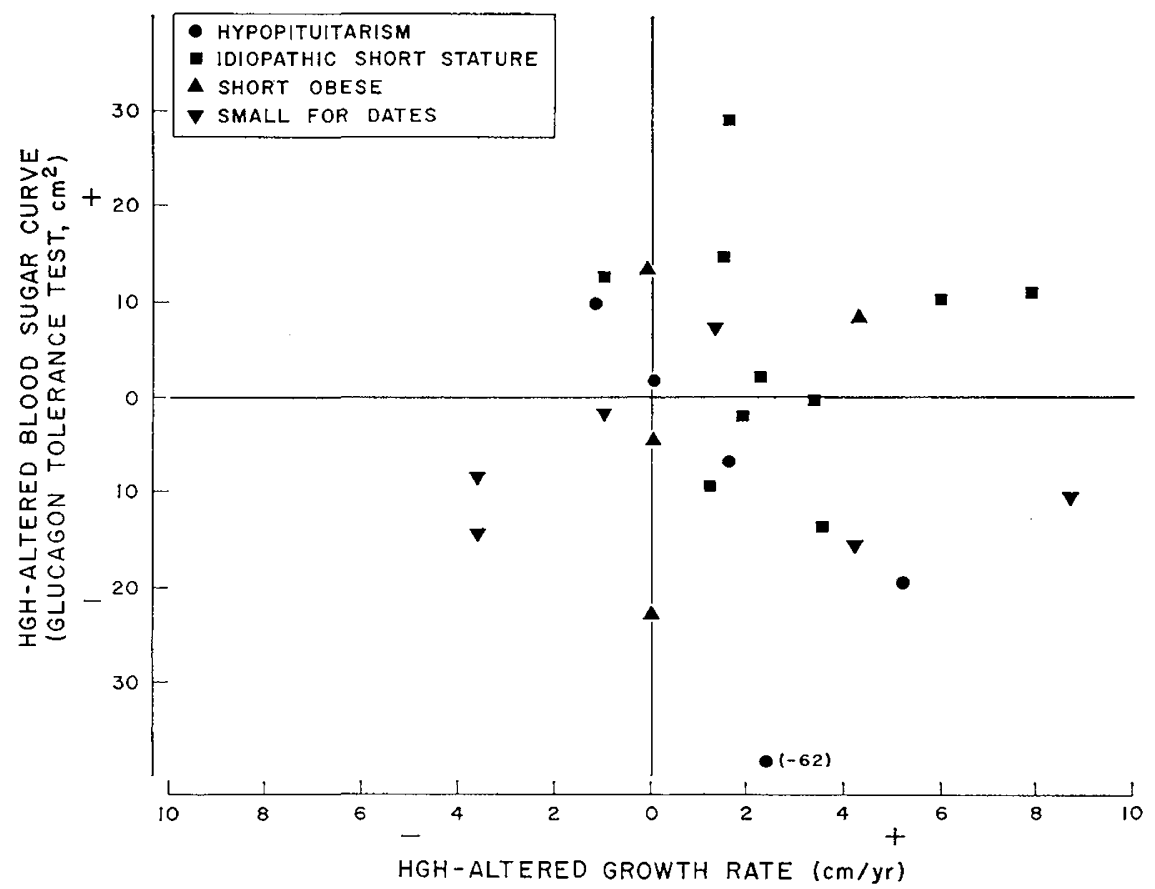

Fig. 5. Comparison of $\mathrm{HGH}$-altered growth rate and acute $\mathrm{HGH}$-altered blood sugar following glucagon stimulation. HGH: human growth hormone. 
subjects, in six of ten idiopathic short patients, in two of four short obese patients, and in only one of six small-for-date children.

As noted in Figures 1-5, both HGH levels per se and acute responses to $\mathrm{HGH}$ correlated poorly with the long-term effect of HGH on growth. For the entire group of 25 patients, only the HGH-altered BS curves after insulin administration correlated with the HGHaltered rate of growth $(P=0.05)$.

\section{Discussion}

Patients with short stature who have hypopituitarism have been shown to grow much more than controls when treated with $\mathrm{HGH}[5,11,15-18,21,23,26,29]$. In this study only one of the five patients in the hypopituitary group responded with a significant increase in growth rate when treated with HGH alone. Three other patients had markedly increased rates of growth when treated with both HGH and thyroid hormone. Thus, $80 \%$ of the patients in this group ultimately grew in response to HGH treatment. We cannot explain the lack of response in the one hypopituitary patient who did not grow.

In none of the other groups was the long-term response to HGH this impressive. However, seven of the 20 patients $(35 \%)$ in the other three groups increased their rates of growth by at least $3.4 \mathrm{~cm} / \mathrm{yr}$ (Table IV). None of these seven patients had hypopituitarism, although a specific lack of HGH cannot be ruled out with certainty for $J R$ in the short obese group. One of the children in the idiopathic short stature group $(J B)$ was 13 years old when treated with HGH. Although he showed no signs of adolescent development, we cannot rule out an adolescent growth spurt. None

Table $I V$. Growth rates in nonhypopituitary short children who grew in response to human growth hormone (HGH) therapy

\begin{tabular}{lcccc}
\hline & & \multicolumn{3}{c}{ Growth rate, cm/yr } \\
\cline { 3 - 5 } Patient & Group & $\begin{array}{c}\text { Prior to } \\
\text { HGH }\end{array}$ & $\begin{array}{c}\text { During } \\
\text { HGH }\end{array}$ & $\begin{array}{c}\text { After } \\
\text { HGH }\end{array}$ \\
\hline$W F$ & ISS & 2.2 & 8.1 & 3.8 \\
$T W$ & ISS & 1.3 & 9.2 & 5.2 \\
$J B$ & ISS & 6.8 & 10.2 & 4.7 \\
$E S$ & ISS & 4.2 & 7.7 & 2 \\
$J R$ & SO & 2.3 & 6.6 & 2.6 \\
$E R$ & SD & 5.4 & 9.6 & 4.4 \\
$P S$ & SD & 1.6 & 10.3 & $\mathbf{2}$ \\
\hline
\end{tabular}

${ }^{1}$ ISS : idiopathic short stature, SO : short obese, SD : smallfor-date.

2 Patient is still receiving $\mathrm{HGH}$. of the other nonhypopituitary dwarfs who had an HGH-altered rate of growth was this old or showed sexual development during $\mathrm{HGH}$ treatment. It may also be argued that the $3.5 \mathrm{~cm} / \mathrm{yr}$ increase in growth rate shown by $E R$ in the idiopathic short stature group was not great enough to warrant inclusion among those who had a significant HGH-stimulated growth spurt. If these three patients are deleted, there still are 4 of $17(23.5 \%)$ nonhypopituitary dwarfs who responded with significantly increased rates of growth.

Other workers have not found this type of response $[12,16,17,26]$. We cannot explain this discrepancy fully. Perhaps part of the explanation may be found in the relatively few nonhypopituitary dwarfed patients who have been treated with HGH. Many of the nonhypopituitary patients treated with $\mathrm{HGH}$ by others have had pathological findings in addition to their short stature. Several workers have suggested that there are some dwarfed patients who grow poorly because of an abnormal growth hormone or because of defects in end organ responses rather than because of a lack of HGH per se $[4,14,20,25]$. Such patients belong to special groups and include the hereditary dwarfs described by Laron et al. [14], the African Pygmy described by Rimoin et al. [20], the patients with Turner's syndrome as discussed by Daughaday et al. [4], and the children with small-for-date dwarfism recently reported by Tanner and Ham [25] and by Foley $e t$ al. [8]. Since such dwarfed patients (as well as the 7 patients in this study) have seemingly normal or high levels of HGH, these individuals may have a growth hormone which is biologically inactive or a block in the pathway that mediates the growth hormone effect.

There are at least two possible explanations why those short individuals with normal HGH levels did not respond to exogenous HGH. Some of them may have a deficiency or abnormality of their sulfation factor [4]. Others may have an abnormal end organ responsiveness.

The four groups of short children were chosen for study partly because of their divergent HGH levels. It was hoped that long-term responsiveness to $\mathrm{HGH}$ could be related to endogenous HGH. We were not able to do this with any degree of certainty. Even when the obese patients are eliminated (obesity is associated with low levels of plasma $\mathrm{HGH}$ despite the usual normal or above-normal rates of growth [20, 27]), growth did not correlate with endogenous HGH levels in the remaining patients. This may be due to the relatively few patients in each group, but also is very likely a reflection of the fact that short stature may 
be caused by an abnormality in any portion of the pathway that mediates the HGH effect and is not necessarily due to a deficiency of HGH.

The very high maximal levels of $\mathrm{HGH}$ seen in five of six patients in the small-for-date group and in one of the patients in the idiopathic short stature group $(N M)$ suggest the possibility of an abnormality in a feedback mechanism in the control of HGH secretion. No such mechanism has been described previously. However, the elevated HGH levels observed in these patients are reminiscent of similar elevated levels of trophic hormones seen in thyroidectomized and adrenalectomized patients.

Some workers have found that the increased retention of nitrogen following HGH treatment is a good index of which patients will grow when treated with $\mathrm{HGH}$ on a long-term basis [15-17, 29]. We were not able to relate the degree of increased nitrogen retention to subsequent growth in our patients. The primary difference in our study as compared with those of others was the amount of HGH used. Our patients were given one IU HGH daily during the nitrogen balance study. In contrast, most patients studied by others were given 2-5 times as much hormone. In oux study neither nitrogen retention nor any of the other acute responses correlated well with subsequent growth. The only acute response in this study which correlated at all with subsequent growth was the insulin-stimulated BS change following HGH. However, this correlation was barely significant $(P=0.05)$ and therefore, at best, offers only a fair approach to predicting which patients will grow when treated with $\mathrm{HGH}$.

The continued short supply of HGH, as well as the desirability of treating only those individuals who are most likely to grow in response to this therapy, certainly warrants further study in an effort to predict which short individuals will grow when treated with this hormone.

As noted in Table IV, five of the seven nonhypopituitary short patients who grew in response to $\mathrm{HGH}$ had significantly decreased pretreatment rates of growth for age. This finding may aid in the selection of those short patients who should be treated with $\mathrm{HGH}$.

In addition to the above-mentioned nitrogen retention, another type of acute response has been used successfully in this regard. Daughaday and associates [5] have shown that sulfation factor increased significantly following $\mathrm{HGH}$ in those individuals who subsequently grew when treated with $\mathrm{HGH}$. Those short patients in whom this acute response did not occur did not have a subsequent HGH-induced growth spurt.

From the results of this study it is quite possible that a small but significant number of dwarfed individuals synthesize a biologically abnormal HGH. At this time prediction of the growth response to $\mathrm{HGH}$ treatment in any given individual is most difficult if not impossible. Currently the criterion used most for selection of candidates for $\mathrm{HGH}$ therapy is the presence or absence of endogenous HGH. However, the only sure way of knowing if a patient will respond to HGH is by giving him trial HGH therapy. This approach may be diffcult at the present time due to the shortage of $\mathrm{HGH}$. In addition, caution should always be exercised because of the potential development of $\mathrm{HGH}$ antibodies when HGH therapy is undertaken. However, when synthetic HGH becomes available, there should be no reason why most dwarfed patients with slowed rates of growth should not be given a trial of $\mathrm{HGH}$ therapy.

\section{Summary}

Twenty-five significantly short children were treated with growth hormone after a series of tests of acute responsiveness to $\mathrm{HGH}$. Five had hypopituitarism, 10 had no demonstrable endocrinopathy, four were above the 97 th percentile for weight but below the 3rd percentile for height, and six were small-for-date. Acute responses to $\mathrm{HGH}$ did not permit a determination of those patients who would have a significant growth response when treated with growth hormone. Four of five patients with hypopituitarism grew significantly when treated with thyroid hormone as well as $\mathrm{HGH}$. However, seven of the nonhypopituitary patients with normal or high levels of endogenous growth hormone also grew when treated with HGH. Reassessment of the criteria used to select patients for treatment is discussed.

\section{References and Notes}

1. BAYER, L. M., AND BAYLEy, N.: Growth Diagnosis. (University of Chicago Press, Chicago, 1959).

2. Boden, G., And Solddner, J. S.: A sensitive double antibody radioimmunoassay for human growth hormone (HGH): levels of $\mathrm{HGH}$ following rapid tolbutamide infusion. Diabetologia, 3: 413 (1967).

3. Campbell, W. R., and Hanna, M. I.: The determination of nitrogen by modified Kjeldahl methods. J. Biol. Chem., 119: $l$ (1937).

4. Daughaday, W. H., Laron, Z., And Heins, J. H.: A defective sulfation factor generation a possible etiological link in dwarfism. Clin. Res., 17: 472 (1969).

5. Daughaday, W. H., and Parker, M. L.: Sulfation factor 